\title{
Behavioural intervention to increase physical activity in adults with coronary heart disease in Jordan
}

\author{
Eman Alsaleh ${ }^{1 *}$, Richard Windle ${ }^{2}$ and Holly Blake ${ }^{2}$
}

\begin{abstract}
Background: Patients with coronary heart disease often do not follow prescribed physical activity recommendations. The aim of this study was to assess the efficacy of a behavioural intervention to increase physical activity in patients with coronary heart disease not attending structured cardiac rehabilitation programmes.

Methods: Parallel randomised controlled trial comparing 6-month multi-component behavioural change intervention $(n=71)$ with usual care $(n=85)$ was conducted in two hospitals in Jordan, Middle East. Intervention included one face-to-face individualised consultation, 6 telephone support calls (for goal-setting, feedback and self-monitoring) and 18 reminder text messages. Patients were randomly allocated to the two groups by opening opaque sealed sequence envelopes. The patients and the researcher who provided the intervention and assessed the outcomes were not blinded. Outcomes were assessed at baseline and 6 months. Primary outcome was physical activity level, secondary outcomes were blood pressure, body mass index, exercise self-efficacy for exercise and health-related quality of life.
\end{abstract}

Results: Intervention and control groups were comparable at baseline. Moderate physical activity significantly increased in the intervention group compared with control group (mean change (SD) of frequency: 0.23 (0.87) days/week versus -.06 (0.40); duration: 15.53 (90.15) minutes/week versus -3.67 (22.60) minutes/week; intensity: 31.05 (105.98) Metabolic equivalents (METs) versus 14.68 (90.40) METs). Effect size was 0.03 for moderate PA frequency, 0.02 for moderate PA duration and 0.01 for moderate PA intensity. Walking significantly increased in the intervention group compared with control group (mean change (SD) of frequency: 3.15 (2.75) days/week versus 0.37 (1.83) days/week; duration: 150.90 (124.47) minutes/week versus 24.05 (195.93) minutes/week; intensity: 495. 12 (413.74) METs versus 14.62 (265.06) METs). Effect size was 0.36 for walking frequency, 0.05 for walking duration, 0.32 for walking intensity and 0.29 for total PA intensity. Intervention participants had significantly lower blood pressure, lower body mass index, greater exercise self-efficacy and better health-related quality of life at 6 months compared with controls.

Conclusions: Multi-component behavioural intervention increases physical activity, and improves body composition, physiological and psychological outcomes in CHD patients not attending structured rehabilitation programmes.

Trial registration: Current Controlled Trials retrospectively registered in 21-03-2012. ISRCTN48570595.

Keywords: Coronary heart disease, Physical activity, Intervention, Behavioural, Self-efficacy

* Correspondence: emanamflower1@yahoo.com

${ }^{1}$ School of Nursing, Philadelphia University, Amman, Jordan

Full list of author information is available at the end of the article

(c) 2016 The Author(s). Open Access This article is distributed under the terms of the Creative Commons Attribution 4.0 International License (http://creativecommons.org/licenses/by/4.0/, which permits unrestricted use, distribution, and reproduction in any medium, provided you give appropriate credit to the original author(s) and the source, provide a link to the Creative Commons license, and indicate if changes were made. The Creative Commons Public Domain Dedication waiver (http://creativecommons.org/publicdomain/zero/1.0/) applies to the data made available in this article, unless otherwise stated. 


\section{Background}

Regular physical activity (PA) is recommended for coronary heart disease (CHD) patients for its role in the prevention and treatment of CHD risk factors such as hypertension and overweight [1-3] and positive benefits for quality of life $[4,5]$. However, PA levels are consistently low among CHD patients [3, 6-9]. Inaccessibility or a lack of availability of PA programmes is an important factor in adherence to PA in CHD patients [10-12]. In Jordan, which is a developing country, challenges within the healthcare systems mean that the availability of structured PA rehabilitation programmes is poor [13]. Many Jordanian CHD patients do not adhere to general PA recommendations $[13,14]$ and report factors influencing engagement in PA which include low self-efficacy (or confidence) for PA, perceived barriers to PA and low motivation to be active $[14,15]$.

Behavioural change interventions have shown efficacy in increasing PA levels in CHD patients and improving psychosocial health [16-18], and often include strategies such as goal-setting, self-monitoring and feedback. Goal-setting has been found to be more effective when goals are short-term [19-21], specific [22-24] and set by patients or in collaboration with healthcare professionals (rather than by them) [25]. Self-monitoring using diaries or records has been found to be useful in raising awareness about existing behaviour [26] and increasing PA [4]; regular follow-ups and contacts by healthcare professionals are thought to enhance patients' self-monitoring of goal achievements [19-21].

Studies have demonstrated the value of delivering behavioural change strategies through face-to-face consultation, and telephone follow-up [4, 27]. Mobile phone text messages are increasingly used to support healthcare, and have shown benefits for increasing PA in other settings [28]; text message reminders may therefore provide a useful mechanism for low-cost provision of regular patient contact.

In practice, behavioural change strategies are not implemented widely in either supervised or non-supervised PA interventions with CHD patients [4]. Whilst previous behavioural change interventions have shown some efficacy in increasing PA, research studies have been criticised for failing to provide sufficient detail about the behavioural change strategies employed, and the interventions have been criticised for lacking focus on addressing individual patients' needs and a lack of provision of regular feedback to patients on their progress [18, 27, 29-32].

This study aimed to examine the efficacy of a behavioural change intervention to increase PA in Jordanian patients with CHD, through building self-efficacy (or confidence) for exercise, addressing barriers to exercise and motivating health behaviour change through tailored goal setting, feedback, monitoring and reminders.
The efficacy of the intervention in improving secondary outcomes was assessed, including: blood pressure (BP), body mass index (BMI), exercises self-efficacy and health-related quality of life (HRQL). This paper reports the components of the intervention, the results of the primary and secondary outcomes, the discussion of the findings and the implication of the intervention in the practice and research.

\section{Methods \\ Study design}

This was a multicentre randomised controlled trial, and parallel group study. Consolidated Standards of Reporting Trials (CONSORT) statement guidelines were adopted in conducting and reporting the trial [33]. Ethical approval for the study was granted in the UK by the local institutional review board, and in Jordan by the institutional review boards at both participating hospital sites (Jordan University Hospital and King Abdullah University Hospital).

\section{Participants}

The target population were Jordanian outpatients with CHD, that met the following eligibility criteria: a) were clinically stable and able to perform PA; b) were adults between the ages of 18 and 70 years; c) had access to a mobile telephone and; d) had no co-morbidities or unstable major health problems that prevented them from participation in PA. Sample size calculations indicated that a total sample size of 156 participants was required accounting for up to $15 \%$ loss to follow-up based on a conservative estimate taken from previous studies [22, 27]. Statistical power was calculated based on the difference in mean change of PA amount (minutes per week) between the control and intervention groups as identified in previous studies [34]. This was to detect improvements in PA level of 30 min per week, which was deemed to be a moderately large clinically relevant difference between the control and intervention group [34]. This had an estimated standard deviation of 60 with a two-sided $5 \%$ significance level and a power of $80 \%$.

\section{Procedure}

Potential participants were identified from hospital records by the researcher and screened for eligibility. Consulting physicians were asked to confirm whether eligible participants were medically stable and capable of performing PA at the recommended level advised for the general population and the majority of $\mathrm{CHD}$ patients at the time of the study (30-60 min of moderate intensity PA on most, or preferably all days of the week). Once eligibility was confirmed, the researcher approached suitable patients in the outpatient clinics and provided them with study information sheets containing contact details 
for the researcher. Interested participants then contacted the researcher who arranged a suitable time to take informed consent at the hospital clinic, following which they were recruited into the study and baseline data collected. Recruitment and baseline data collection took place between February and March 2012.

Recruited participants were randomised to one of two groups. Randomisation was undertaken using prepared opaque sealed envelopes, by a researcher who was not involved in recruitment or the delivery of the intervention. Group 1 received usual care from their physicians, which consisted of general (rather than tailored) advice about the benefits of PA and instructions to engage in moderate-intensity PA, such as brisk walking. Group 2 received usual care, plus a six-month behavioural intervention delivered by a cardiac nurse. The intervention was delivered to all participants allocated to treatment by a single cardiac nurse who had training in lifestyle advice, and prior expertise in delivering health education and interventions using motivational interviewing techniques with cardiac patients. This ensured that the intervention was delivered consistently to all participants (with respect to length and duration of contacts and extent of advice given), and ensured intervention fidelity.

The intervention was delivered between February and August 2012. The ultimate objective of the intervention was to encourage participants to meet recommendations for daily PA at the time of the study; to engage in 'moderate PA for at least 30 min on most, preferably all, days of the week' $[35,36]$. The intervention was informed by Social Cognitive Theory and Self-Efficacy Theory [37, 38] and adopted behavioural change strategies (goal-setting, self-monitoring, feedback) that were aimed at increasing PA levels. In an initial face-to-face consultation lasting 20-30 min, the cardiac nurse used motivational interviewing techniques to discuss and address patients' barriers to PA, highlight perceived facilitators of active lifestyles, increase self-efficacy for PA and work collaboratively with them to set goals (initiated by the patient). Patients were encouraged to selfset achievable goals that were specific, individualised and short-term. Efforts to enhance self-efficacy involved highlighting patients' achievements of their goals (performance accomplishment), providing feedback on their goal achievements (verbal encouragement), providing patients with encouragement statements on their progress in achieving their goals (vicarious experience) and helping patients to identify their positive perceptions about PA and correct their negative thoughts about PA (physiological and emotional status in capabilities). Patients were encouraged to self-monitor their PA levels through regularly recording their PA in a diary. Each patient then received six telephone call-based consultations with the same nurse (15-20 min each, one per month). In these consultation calls, the nurse provided tailored feedback on patients' engagement in PA, reviewed their goals and diary notes and addressed any arising barriers to patients achieving their goals. Although nurse contact was relatively brief per contact, the frequency and duration of face-to-face and telephone call consultations was determined based on published evidence from studies with healthy people and patients with CHD (Furber et al., [27]; Hughes et al., [30]; Rodrigues et al., [18]). During the intervention period, patients received prompts and reminders to be physically active and meet personal goals, which were sent by mobile phone text message from a no-reply study telephone number. Text message content was based on reminding patients to perform and maintain the required level of PA and encouraging them to address barriers to PA. In addition, the text messages were informed by the Theory of Planned Behaviour (TPB) $[39,40]$; targeting attitudes, subjective norms, perceived behavioural control and intention. In total, 18 reminder text messages were delivered to each patient at a rate of two messages every week in the first 3 months and one message every week in the last 3 months; since interventions using individualised or decreasing frequency of messages may be more successful than interventions using a fixed message frequency [41].

Outcome data were collected at two time points: baseline (immediately after recruitment) and immediately post-intervention (6 months after randomisation). The researcher collected questionnaire measures via structured interview, and at the same appointment, collected physiological and body composition measures. Three months after the end of the intervention (9 months after randomisation), participants in the intervention group were invited to complete a questionnaire survey to assess their perceptions of the intervention, current engagement in physical activity (meeting PA guidelines, or not) and PA intentions. Flow of participants through the study is provided in Fig. 1.

\section{Measures}

\section{Socio-demographic and health information}

The questionnaire included socio-demographic items (age, gender, marital status, living status and area, educational level, job status, income), items relating to CHD diagnosis and duration and co-morbidities, together with general health items (single item measures of diet, smoking behaviour and general health perception). Standardised questionnaire measures included PA, self-efficacy for exercise and HRQL. Physiological and body composition measures included blood pressure, height and weight. 


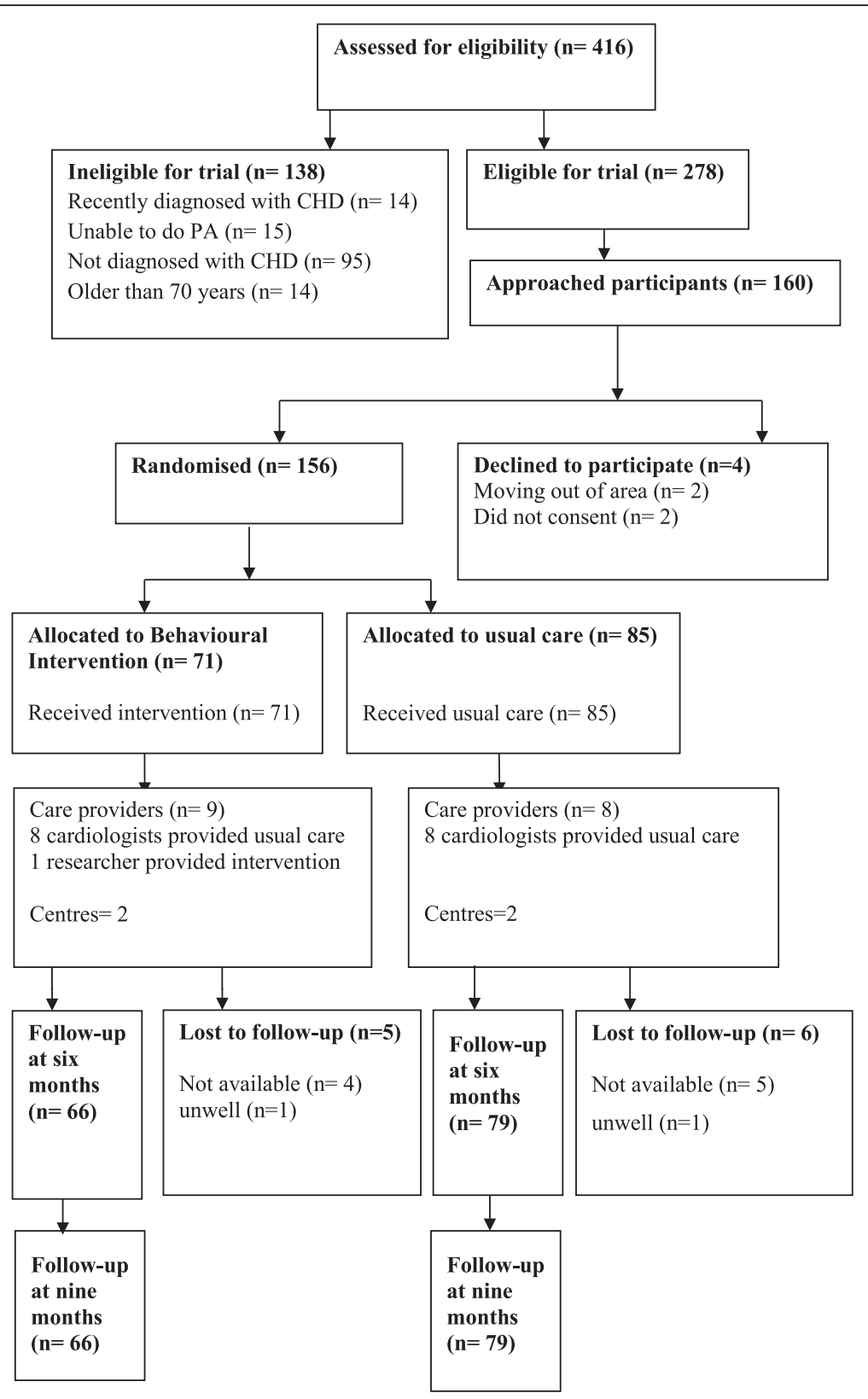

Fig. 1 Flow of participants through the study

\section{Questionnaire measures Physical activity}

Self-reported moderate PA and walking was measured using the short format of the International Physical Activity Questionnaire [IPAQ, 42] which has established reliability and validity [43]. This questionnaire contains four domains of PA: leisure time, domestic and gardening, work and transport related PA, and includes specific types of PA: walking, moderate-intensity and vigorous-intensity activity. Items relating to vigorous PA were not included since the CHD patients were not encouraged to perform PA at this level. Individuals reported their level of PA by writing the frequency (days per week) and duration (minutes per day) of each type of activity. To measure intensity of PA, metabolic equivalents (METs) were calculated.

\section{Self-efficacy for exercise}

Exercise self-efficacy was assessed using the Exercise Self-Efficacy Scale (ESES) which has established reliability and validity [44]. The scale incorporates nine items that describe situations in which people might experience difficulties in engaging in regular PA. Respondents rated their perceived ability to perform 
moderate physical activity in a range of circumstances, from 0 (not confident) to 10 (very confident). The total score was obtained by summing the numerical rating for each answer and dividing by the number of answers.

\section{Health-related quality of life}

HRQL was measured by the Mac-New Heart Disease HRQL [45] which has established validity and reliability, and has been shown to be acceptable to patients with CHD [46, 47]. This 27-item questionnaire evaluates the QOL aspects of physical, emotional and social functioning affected by CHD. Items are presented on a Likert scale ranging from one (indicating low HRQL) to seven (indicating high HRQL) [45].

\section{Physiological outcomes and body composition Diastolic \& systolic blood pressure}

Blood pressure was measured by the researcher in the cardiac clinic with an automated electronic blood pressure monitor, using criteria determined by the American Heart Association [48], the British Hypertension Society [49] and the Medicines and Health Care Products Regulatory Agency [50]. The same monitor was utilised for all patients at baseline and at six months. A validity test was undertaken by taking four readings alternating with five mercury sphygmomanometer readings [51]. Both systolic and diastolic readings taken were at least within $5 \mathrm{mmHg}$ of each other for at least $50 \%$ of readings.

\section{Body mass index}

BMI was calculated from weight and height using the following formula: $\mathrm{BMI}=$ [weight in kilograms $/[$ height in metres $\mathrm{x}$ height in metres]]. Individuals were classified into categories according to their BMI $(<18.5=$ underweight, $18.5-24.9=$ normal weight, $25-29.9=$ overweight, $>30=$ obese).

\section{Data analysis}

Statistical analysis was conducted using SPSS for Windows version 20.0. Independent $t$-test was used to measure baseline to six-month changes of PA and secondary outcomes in both groups, and mean difference of mean changes of PA levels and secondary outcomes between control and intervention groups. Complete case analysis was utilised since missing data was considered to be 'missing completely at random' (MCAR). Intention to treat analysis (ITT) was adopted including multiple imputation and last observation carried forward. Independent $t$-test and chi-squared test were used to compare the demographic profile of the intervention with control group at baseline, and responders with nonresponders at 6-month follow-up.

\section{Results}

One hundred and fifty six participants were randomly allocated to the control $(n=85)$ and intervention groups $(n=71)$. Sociodemographic and health characteristics were not significantly different between the control and intervention groups at baseline (see Table 1). Study participants were comparable with the population from which they were drawn in terms of age, gender and medical diagnosis. All intervention participants $(n=71$; $100 \%)$ completed all six months of the intervention; low rates of loss to follow-up were observed (see Fig. 1).

Sixty Five (92\%) of intervention participants completed at least one goal in the PA diary, and 66 (93\%) completed diaries for all 12 weeks of the intervention period. Adherence to completion of physical activity diaries dropped $3 \%$ across the intervention period. Diary content and accomplishment of goals was not formally measured as an outcome, but was discussed within telephone consultations with the nurse as part of the process of tailored feedback and goal-setting.

\section{Physical activity}

Participants were classified as physically active according to IPAQ when they met the PA guidelines of performing $30 \mathrm{~min}$ of moderate intensity PA five days a week (150 min per week), or through a combination of walking and moderate-intensity activities they achieved a minimum of at least $600 \mathrm{METs}$ - minutes/week. There were no significant differences in PA at baseline, between groups. One quarter of the sample met PA recommendations at baseline (intervention: $n=17,24 \%$; control: $n=22,26 \%)$. The proportion of participants meeting recommendations for daily PA significantly increased from baseline to six months in the intervention group (baseline: $n=17,24 \%$; six months: $n=58 ; 88 \%$ ) and decreased in the control group (baseline: $n=22$, $26 \%$; six months: $n=19 ; 24 \%)$. Mean scores for moderate PA and walking levels (including frequency, duration and intensity) significantly increased from baseline to six-months in the intervention group but not in the control group. The difference in mean change of walking and moderate PA levels between the two groups was high. Mean change (SD) and mean difference (95\% confidence intervals) are shown in Table 2.

\section{Secondary outcomes \\ Health-related quality of life}

HRQL increased from baseline to six-months in the intervention group but not in the control group. There was a significant difference between intervention and control groups in total HRQL and all three domains including physical, social and emotional domains. The difference in mean change of HRQL between the two 
Table 1 Sociodemographic and health characteristics

\begin{tabular}{|c|c|c|c|}
\hline Characteristics & $\begin{array}{l}\text { Control } \\
(n=85)\end{array}$ & $\begin{array}{l}\text { Intervention } \\
(n=71)\end{array}$ & $p$ \\
\hline Age & $58 \pm 8.7$ & $57.7 \pm 10.5$ & 0.49 \\
\hline \multicolumn{4}{|l|}{ Gender } \\
\hline Male & $43(50.6)$ & $41(57.7)$ & \multirow[t]{2}{*}{0.42} \\
\hline Female & $42(49.4)$ & $30(42.3)$ & \\
\hline \multicolumn{4}{|l|}{ Monthly income } \\
\hline$<99$ Jordanian dinars & $6(7.1)$ & $6(8.5)$ & \multirow[t]{4}{*}{0.60} \\
\hline 100-299 Jordanian dinars & $28(32.9)$ & $26(36.6)$ & \\
\hline 300-499 Jordanian dinars & $30(35.3)$ & $18(25.4)$ & \\
\hline$>500$ Jordanian dinars & $21(24.7)$ & $21(29.6)$ & \\
\hline \multicolumn{4}{|l|}{ Education level } \\
\hline Primary & $28(32.9)$ & $29(40.8)$ & \multirow[t]{4}{*}{0.79} \\
\hline Secondary & $21(24.7)$ & $14(19.7)$ & \\
\hline University & $33(38.8)$ & $26(36.6)$ & \\
\hline None & $3(3.5)$ & $2(2.8)$ & \\
\hline \multicolumn{4}{|l|}{ Marital status } \\
\hline Single & $5(5.9)$ & $5(7)$ & \multirow[t]{4}{*}{0.73} \\
\hline Married & $70(82.4)$ & $61(85.9)$ & \\
\hline Divorced & $1(1.2)$ & $1(1.4)$ & \\
\hline Widowed & $9(10.6)$ & $4(5.0)$ & \\
\hline \multicolumn{4}{|l|}{ Living status } \\
\hline Alone & $6(7.1)$ & $4(5.6)$ & \multirow[t]{3}{*}{0.78} \\
\hline With spouse & $4(4.7)$ & $5(7)$ & \\
\hline With spouse \& children & 75 (88.2) & $62(87.3)$ & \\
\hline \multicolumn{4}{|l|}{ Job status } \\
\hline Working & $21(21.7)$ & $20(28.2)$ & \multirow[t]{3}{*}{0.81} \\
\hline Not working & $45(52.9)$ & $34(47.9)$ & \\
\hline Retired & $19(22.4)$ & $17(23.9)$ & \\
\hline \multicolumn{4}{|l|}{ Living area } \\
\hline City & 75 (88.2) & $60(84.5)$ & \multirow[t]{3}{*}{0.63} \\
\hline Town & $4(4.7)$ & $6(8.5)$ & \\
\hline Village & $6(7.1)$ & $5(7)$ & \\
\hline \multicolumn{4}{|l|}{ Current CHD } \\
\hline Chest pain & $16(18.8)$ & $8(11.3)$ & \multirow[t]{4}{*}{0.24} \\
\hline Catheterization & $59(69.4)$ & $54(76.1)$ & \\
\hline Cardiac surgery & $10(11.8)$ & $7(9.9)$ & \\
\hline Myocardial infarction & $0.0(0.0)$ & $2(2.8)$ & \\
\hline Duration of diagnosis & $61.5 \pm 60.8$ & $48.3 \pm 45.3$ & 0.13 \\
\hline \multicolumn{4}{|l|}{ Chronic disease } \\
\hline Diabetes & $6(7.1)$ & $8(11.3)$ & \multirow[t]{4}{*}{0.63} \\
\hline Hypertension & $33(38.8)$ & $22(31.0)$ & \\
\hline Diabetes \& hypertension & $29(34.1)$ & $24(33.8)$ & \\
\hline None & $17(20)$ & $17(23.9)$ & \\
\hline
\end{tabular}

Values are mean values \pm SD or numbers and percentages in parenthesis groups was high. Mean change (SD) and mean difference (95\% confidence intervals) are shown in Table 3.

\section{Self-efficacy for exercise}

Exercise self-efficacy scale increased from baseline to six-months in the intervention group but not in the control group. The difference in mean change of exercise self-efficacy between the two groups was high. Mean change (SD) and mean difference (95\% confidence intervals) are shown in Table 3.

\section{Physiological outcomes and body composition}

Systolic \& diastolic blood pressure There was a significant decrease in mean value of SBP and DBP from baseline to six-months among the intervention group but not in the control group, indicating a significant difference in the mean change of SBP and DBP between intervention and control groups (Table 3).

Weight and body mass index Mean body weight and BMI decreased significantly from baseline to six-months among the intervention group but not among the control group, indicating a significant difference in the mean change of body weight and BMI between intervention and control groups (see Table 3). The majority of patients in both intervention and control groups were overweight or obese at baseline $(84.5 \%$ and $87 \%$ respectively); at six months there was a significant difference in the distribution of body weight between the two groups $(p=0.007)$. At six months there were more patients with normal body weight and fewer who were overweight or obese in the intervention group compared with those in the control group (Table 4).

\section{Participants' perceptions of the intervention}

Of the intervention participants, $n=66$ (92.96 \%) completed the post-intervention evaluation survey (three months after the intervention ended). Perceptions of the intervention were positive, with $100 \%$ reporting that they valued all elements of the intervention, including goal-setting, self-monitoring and feedback and delivery methods including face-to-face consultation, telephone call consultations and text messages. Participants reported multiple benefits of the intervention, which included: gaining knowledge about how to make behavioural changes, receiving regular reminders and encouragement which motivated them to be more active, and feeling supported by and building a trusting relationship with the cardiac nurse. A minority of participants $(n=13)$ raised barriers to being active after the intervention; these included being in poor health, not having enough time and not enjoying PA. The majority of participants reported that they had overcome their barriers to PA through engaging with the intervention, learning 
Table $\mathbf{2}$ Change in physical activity levels between control and intervention groups

\begin{tabular}{|c|c|c|c|c|c|c|c|}
\hline \multirow{2}{*}{$\begin{array}{l}\text { PA levels } \\
\text { Moderate PA }\end{array}$} & \multicolumn{2}{|l|}{ Control $(n=79)$} & \multicolumn{2}{|c|}{ Intervention $(n=66)$} & \multicolumn{2}{|c|}{ Mean change (SD) } & \multirow{2}{*}{$\begin{array}{l}\text { Mean difference } \\
(95 \% \mathrm{Cl})\end{array}$} \\
\hline & $\begin{array}{l}\text { Baseline mean } \\
\text { (SD) }\end{array}$ & $\begin{array}{l}6 \text { months } \\
\text { mean (SD) }\end{array}$ & $\begin{array}{l}\text { Baseline mean } \\
\text { (SD) }\end{array}$ & $\begin{array}{l}6 \text { months } \\
\text { mean (SD) }\end{array}$ & $\begin{array}{l}\text { Control group } \\
(n=79)\end{array}$ & $\begin{array}{l}\text { Intervention } \\
\text { group }(n=66)\end{array}$ & \\
\hline Frequency & $0.45(1.31)$ & $0.39(1.27)$ & $0.70(1.67)$ & $0.93(1.85)$ & $-.06(0.40)$ & $0.23(0.87)$ & $-0.29 *(-0.51$ to -0.07$)$ \\
\hline Duration & $20.13(62.50)$ & $16.46(58.73)$ & $21.14(44.95)$ & $36.67(109.76)$ & $-3.67(22.60)$ & $15.53(90.15)$ & $-19.20^{*}(-39.98$ to -1.58$)$ \\
\hline $\begin{array}{l}\text { Intensity } \\
\text { walking }\end{array}$ & $77.97(243.13)$ & $63.29(227.41)$ & $83.18(178.02)$ & $114.23(212.60)$ & $-14.68(90.40)$ & 31.05 (105.98) & $-45.73^{*}(-77.97$ to -13.50$)$ \\
\hline Frequency & $3.03(2.55)$ & $3.40(2.36)$ & $3.0(2.37)$ & $6.15(1.26)$ & $0.37(1.83)$ & $3.15(2.75)$ & $-2.78^{*}(-3.57$ to -2.00$)$ \\
\hline Duration & $84.81(90.98)$ & $108.86(198.02)$ & $86.97(99.11)$ & $237.88(121.10)$ & 24.05 (195.93) & $150.90(124.47)$ & $-126.86^{*}(-179.96$ to -73.76$)$ \\
\hline Intensity & $275.16(300.71)$ & 289.78 (302.74) & $276.52(301.63)$ & 771.64 (396.44) & $14.62(265.06)$ & $495.12(413.74)$ & $-480.61^{*}(-597.61$ to 363.61$)$ \\
\hline Total intensity & $353.14(415.29)$ & $353.08(406.88)$ & $359.70(598.27)$ & $886(426.52)$ & $-0.06(271.33)$ & $526.30(394.12)$ & $\begin{array}{l}-526.24^{*}(-639.91 \text { to } \\
-412.78)\end{array}$ \\
\hline
\end{tabular}

PA: physical activity, frequency was measured by days/week, duration was measured by minutes/week, intensity was measured by METs/week, *: significant difference when $P<0.05$

and implementing behavioural change strategies and increasing their knowledge about the importance of PA for their health.

At nine months, all those participants that were engaging in recommended levels of PA at six months $(n=58,88 \%)$ indicated that they had maintained this level of PA over the previous three months; of the inactive remainder, $9 \%(n=$ 6) reported a positive intention to increase their PA levels.

\section{Discussion}

This behavioural intervention was effective in increasing PA levels among patients with CHD and helping them to achieve the internationally recommended levels of daily PA required to benefit their health. The high recruitment rates, low attrition rates and positive feedback from intervention participants demonstrate the attractiveness and acceptability of this theory-based behaviour change intervention to CHD patients in Jordan.
The intervention was highly accessible to CHD patients. Firstly, it did not require their attendance at a supervised PA program. Secondly, the prescribed PA was walking which is a safe yet effective form of physical activity which can be undertaken without supervision and is therefore suitable for CHD patients [35, 52].

Findings are limited by self-reported measures of physical activity. Although the IPAQ is a valid and reliable measure of PA, self-reports, may give a distorted impression of PA levels (usually an overestimation) compared to objective measures of PA [53, 54]. However, standardized interviews were conducted when administering the questionnaire in order to minimize guessing and over or underestimating of PA levels, which may occur when patients fill in questionnaires on their own [55].

Additionally, the increase in frequency, duration and intensity of physical activity observed in this study was substantially larger than that reported in many previous PA-based behavioural interventions among CHD

Table 3 Changes in secondary outcomes between control and intervention groups

\begin{tabular}{|c|c|c|c|c|c|c|c|}
\hline \multirow[t]{2}{*}{ Health variables } & \multicolumn{2}{|l|}{ Control $(n=79)$} & \multicolumn{2}{|c|}{ Intervention $(n=66)$} & \multicolumn{2}{|c|}{ Mean change (SD) } & \multirow{2}{*}{$\begin{array}{l}\text { Mean difference } \\
(95 \% \mathrm{Cl})\end{array}$} \\
\hline & $\begin{array}{l}\text { Baseline M } \\
\text { (SD) }\end{array}$ & $\begin{array}{l}6 \text { months } M \\
\text { (SD) }\end{array}$ & $\begin{array}{l}\text { Baseline } M \\
\text { (SD) }\end{array}$ & $\begin{array}{l}6 \text { months } M \\
(S D)\end{array}$ & $\begin{array}{l}\text { Control group } \\
(n=79)\end{array}$ & $\begin{array}{l}\text { Intervention } \\
\text { group } \\
(n=66)\end{array}$ & \\
\hline $\mathrm{SBP}(\mathrm{mm} \mathrm{Hg})$ & $138.82(18.20)$ & 139.39 (14.06) & $134.92(17.59)$ & $128.80(14.27)$ & $.57(11.47)$ & $-6.12(10.79)$ & $6.69 *$ (3.01 to 10.37 ) \\
\hline $\mathrm{DBP}(\mathrm{mm} \mathrm{Hg})$ & $78.16(9.88)$ & $82.96(6.48)$ & $75.71(10.89)$ & $73.92(8.68)$ & $4.80(7.82)$ & $-1.79(5)$ & $6.59 *$ (4.46 to 8.71$)$ \\
\hline Body weight (K gm) & $84.50(31.21)$ & $84.66(32.20)$ & $84(30.20)$ & $78.70(21.31)$ & $0.16(11.20)$ & $-5.30(10.32)$ & $5.46^{*}$ (2.24 to 8.52$)$ \\
\hline Body mass index $\left(\mathrm{kg} / \mathrm{m}^{2}\right)$ & $30.29(6.09)$ & $30.74(5.50)$ & $29.38(5.40)$ & $27.52(5.47)$ & $0.45(2.41)$ & $-1.85(2.14)$ & $2.30^{*}$ (1.54 to 3.06$)$ \\
\hline HRQL (1-7) & $3.85(1.05)$ & $3.70(1)$ & $4.21(0.83)$ & $5.30(0.70)$ & $-0.15(0.60)$ & $1.09(0.66)$ & $-1.24^{*}(-1.45$ to -1.03$)$ \\
\hline Emotional domain (1-7) & $4.04(1.13)$ & $3.90(1.11)$ & $4.51(0.96)$ & $5.59(0.67)$ & $-0.14(0.59)$ & $1.08(0.78)$ & $-1.22^{*}(-1.45$ to 0.99$)$ \\
\hline Social domain (1-7) & $3.98(1.19)$ & $3.80(1.11)$ & $4.26(0.87)$ & $5.20(0.78)$ & $-0.18(0.73)$ & $0.94(0.68)$ & $-1.12^{*}(-1.36$ to -0.89$)$ \\
\hline Physical domain (1-7) & $3.50(1.18)$ & $3.38(1.09)$ & $3.82(0.92)$ & $4.93(0.86)$ & $-0.12(0.77)$ & $1.11(0.75)$ & $-1.23^{*}(-1.48$ to -0.98$)$ \\
\hline Exercise self-efficacy (1-10) & $3.35(1.69)$ & $3.33(1.67)$ & $3.44(1.62)$ & $7.21(0.88)$ & $-0.02(0.89)$ & $3.77(1.56)$ & $-3.79^{*}(-4.23$ to -3.37$)$ \\
\hline
\end{tabular}

SBP systolic blood pressure, DBP diastolic blood pressure, HRQL health related quality of life, *: significant difference when $P<0.05$ 
Table 4 The distribution of body weight based on BMI at baseline and six months between the two study groups

\begin{tabular}{|c|c|c|c|c|c|c|}
\hline \multirow[t]{2}{*}{ Classification of Body weight } & \multicolumn{2}{|l|}{ Baseline } & \multirow{2}{*}{$\begin{array}{l}P \\
0.47\end{array}$} & \multicolumn{2}{|l|}{ Six months } & \multirow{2}{*}{$\begin{array}{l}P \text { value } \\
0.007^{*}\end{array}$} \\
\hline & $\begin{array}{l}\text { Control group } \\
(n=85)\end{array}$ & $\begin{array}{l}\text { Intervention group } \\
(n=71)\end{array}$ & & $\begin{array}{l}\text { Control group } \\
(n=79)\end{array}$ & $\begin{array}{l}\text { Intervention group } \\
(n=66)\end{array}$ & \\
\hline Underweight $\left(<18 \mathrm{~kg} / \mathrm{m}^{2}\right)$ & $(0.0)$ & $1(1.4)$ & & $0.0(0.0)$ & $2(3)$ & \\
\hline Normal weight $\left(18.5-24.9 \mathrm{~kg} / \mathrm{m}^{2}\right)$ & $11(12.29)$ & $10(14.4)$ & & $4(5.1)$ & $16(24.2)$ & \\
\hline Overweight (25-29.9kg/m²) & $32(37.6)$ & $26(36.6)$ & & $32(40.5)$ & $23(34.8)$ & \\
\hline Obese $\left(>30 \mathrm{~kg} / \mathrm{m}^{2}\right)$ & $42(49.4)$ & $34(47.9)$ & & $43(54.4)$ & $25(37.9)$ & \\
\hline
\end{tabular}

patients in either supervised or non-supervised PA programs $[16,27,30,54,56]$. An early study of supervised physical activity with $\mathrm{CHD}$ patients reported a greater increase in total moderate PA intensity and walking behaviour than we found here (supervised PA: 2058 METs/week; our study 886 METs/week) [54]. However, Heath and colleagues delivered a vigorous intensity physical activity intervention [57], and current guidance specifies that moderate PA (as we promoted) is clinically recommended for patients with $\mathrm{CHD}[58,59]$. The success of our intervention may in part be due to the implementation of a theoretically-driven intervention in which multiple behavioural change strategies were adopted. We encouraged patients to set personal tailored goals according to their needs; as such their goals were self-set, specific and personally relevant. Previous interventions had used generic 'one-size-fits-all' goals for their intervention participants [18, 27, 30-32, 34]. Our intervention included active self-monitoring strategies, in which participants were encouraged to record their activity levels in a diary, self-monitor their own progress and make their own plans to achieve their goals based on these observations. In previous studies, physical activity monitoring appeared to be more passive, involving the use of devices (such as accelerometers or pedometers) for automated recording of physical activity levels without participants taking responsibility for actively recording their behaviour or using the information to set tailored goals [27, 30, 31, 34].

Our intervention included regular tailored feedback for participants, which helped them to set their own goals; the combination of feedback with self-monitoring and goal-setting approaches had not been used in many previous PA interventions among CHD patients [22, 27, 30].

This intervention included regular follow-ups, individualised consultations and repeated reminders to act sent by text messages. Although the optimal frequency of follow-ups for PA behavioural interventions is unclear [60] it has been documented that frequent or intense contact between the participants and the health care providers increases the efficacy of PA interventions [16]. Although we do not have behaviour change outcomes beyond six months and as such cannot determine whether behavioural changes were sustained in the long-term, a prior intervention offering lower frequency of contact ( 2 contacts over 6 months) found a decrease in the use of self-regulation skills (goal-setting and self-monitoring) among patients six months after the intervention [27] suggesting that a lower frequency of contact may not result in sustained behavioural change.

The individualised consultations delivered within our intervention included feedback on progress, and tailored advice for patients on setting their own goals, and addressing their personal barriers to exercise. Studies with healthy participants have similarly shown that individualised, personalised consultations for the delivery of behavioural change strategies can successfully increase physical activity levels [61]. Text messaging was used in this study as a mechanism for reminding patients about their commitment to engage in regular PA, and to remind them of strategies that had been discussed to overcome their barriers. Prior research has suggested that using text messages for reminders to achieve goals enhances the mechanism through which implementation intention changes behaviour by improving the accessibility of plans [62].

The intervention improved health-related quality of life and this is consistent with previous PA interventions implemented together with other risk factor management interventions (diet, smoking, stress) in both supervised and home based PA programs among CHD patients $[4,16,29,63,64]$. Follow-up scores for healthrelated quality of life demonstrate that CHD patients in this study had improved health status and decreased impact of the disease following the intervention $[65,66]$. This is an important finding since poor perceived quality of life may impact negatively on an individual's ability to sustain behavioural changes in the long-term.

We observed significant reductions in blood pressure which has important implications for lifelong health. It is possible that patients may have altered their diet or smoking habits, or consumed antihypertensive medications prior to BP measurement. However, the reduction is likely to be associated with concurrent increases in physical activity, and this is consistent with previous studies among healthy people, hypertensive and CHD patients [67-69]. 
The intervention resulted in reductions in body mass index for CHD patients, and this has significant implications for the prevention or management of obesity (84.5\% of our sample were overweight or obese at the outset, compared with $72.7 \%$ at follow-up), and for reducing the risk of co-morbidities. Improved body composition is likely to be associated with increases in physical activity, and improved BMI has been found in physical activity interventions elsewhere [52, 70, 71]. Prior studies have suggested that PA intervention may have little influence on body composition (e.g. body weight) when it is not used in conjunction with dietary intervention $[2,6,72]$. However, this study shows that intervention focused only on PA behaviour can generate clinically significant increases in reported PA activity together with reductions in BMI. This supports a review concluding that PA is associated with changes in body composition (e.g. weight loss) among overweight people even when it is implemented without dietary change methods [73].

Due to the nature of the physical activity intervention, it was not possible to blind participants or the nurse delivering the intervention to group allocation. However, it should be noted that the assessment of outcomes was not undertaken by an independent outcomes assessor, which may incur risk of bias and is a limitation of the study. However, the positive changes in objective variables (including body composition and blood pressure) may be perceived to be indicative of responsiveness to the intervention.

This study had a high participation rate, low attrition, high adherence and positive evaluation from intervention participants. Despite limitations of the study, it is possible that cultural factors may have played a role. Jordan is a developing country and as such, challenges within the healthcare systems that mean that individualised focus on lifestyle behaviours following cardiac incident is limited in scope. In these settings there is an absence of structured cardiac rehabilitation programmes, structured lifestyle advice and tailored intervention, whether as part of hospital and community care, or through research-delivered interventions. This absence of alternative options may have exerted an influence on patients' willingness to participate and fully engage with the intervention, and as such the high rate of positive outcomes observed.

\section{Conclusion}

This behavioural change intervention increased reported PA, improved health and psychological outcomes in CHD patients in Jordan. The intervention contained multiple elements, our magnitude of change was greater than that observed in previous studies, and all aspects of the intervention were perceived positively by participants. Through utilising multiple mechanisms for motivating behaviour change, this study addressed key limitations of prior research $[10-12,14,15,74]$ and we delivered an accessible, theory-based intervention in a setting where lifestyle interventions for $\mathrm{CHD}$ patients are limited, and inaccessibility is a common barrier to physical activity. Firm conclusions cannot be drawn from this study as to which elements of the intervention met with most success, and whether all elements of the intervention are required at the delivered intensity to generate the same magnitude of change. Further research is required to determine the 'dosage' of intervention required to generate physical activity behaviour change. Patients in this study were followed up only at six months and therefore it is not known whether these behavioural changes are sustained in the long-term. However, significant increases in self-efficacy were reported at six months (as found in previous PA interventions) [73, 75]. Increased self-efficacy is important since this intervention aimed to build self-efficacy for exercise, and as such, aimed to provide patients with lifelong skills to self-manage and sustain their own lifestyle behaviours over time. The cost-effectiveness of this intervention needs to be determined. There is scope for investigating pathways for implementing this intervention in new contexts. For example, different settings, as part of supervised PA programs, and/or in combination with other risk management programs (e.g. nutritional management).

\section{Summary illustrations}

- Theory-driven, multicomponent behavioural intervention increases physical activity and improves body composition, health and psychological outcomes among patients with CHD who are not attending supervised PA programs.

- Research is needed to determine the optimal dosage and frequency of intervention required to generate clinically relevant behaviour change and health outcomes.

- Future studies should examine the contribution of individual behaviour change strategies in generating change, and the cost-effectiveness of the intervention.

\section{Abbreviations}

$\mathrm{BMI}$, body mass index; BP, blood pressure; CHD, coronary heart disease; CONSORT, consolidated statement of reporting trials; DPB, diastolic blood pressure; ESES, exercise self-efficacy scale; HRQL, health-related quality of life; IPAQ, International Physical Activity Questionnaire; ITT, intention-to-treat analysis; MCAR, missing completely at random; METs, metabolic equivalents; PA, physical activity; SBP, systolic blood pressure

Acknowledgements

The authors would like to thank all study participants. 


\section{Funding}

This research was supported by a doctoral scholarship from Philadelphia University, Jordan (EA). The funding body was not involved in the design of the study, collection, analysis and interpretation of data, nor in writing the manuscript.

\section{Availability of data and materials}

Request for data access can be made to the corresponding author.

\section{Authors' contributions}

EA and $\mathrm{HB}$ conceived of the study, and led study design. EA led study co-ordination, with contribution relating to the day-to-day running of the study from HB and RW. EA was a doctoral student that worked in the field during intervention at study sites, collected data and undertook analysis with oversight by $\mathrm{HB}$ and RW. $\mathrm{HB}$ and EA drafted the entire manuscript. All authors read and approved the final manuscript.

\section{Authors' information}

For the duration of the study, EA was a doctoral student at the University of Nottingham. She is currently a full-time faculty member at Philadelphia University, Jordan. HB is a full-time faculty member at the University of Nottingham, UK and is Chief Investigator of the study. RW is a full-time faculty member at the University of Nottingham, UK.

\section{Competing interests}

The authors declare that they have no competing interests.

\section{Consent for publication}

Not applicable.

\section{Ethics approval and consent to participate}

This study was approved by the University of Nottingham Institutional Review Board in December 2011, by the King Abdullah University Hospital in December 2011 and by the Jordan University Hospital review board in March 2012. All study participants gave informed, signed consent to participate prior to involvement in the study.

\section{Author details}

${ }^{1}$ School of Nursing, Philadelphia University, Amman, Jordan. ${ }^{2}$ School of Health Sciences, University of Nottingham, Queen's Medical Centre, Nottingham NG7 2HA, UK.

Received: 18 September 2015 Accepted: 15 July 2016 Published online: 26 July 2016

\section{References}

1. World Health Organization (WHO). Global strategy on diet, physical activity and health. Geneva: World Health Organization (WHO); 2004. www.who.int/ dietphysicalactivity/strategy/eb11344/strategy_english_web.pdf. Accessed 14 Jan 2013.

2. Shaw K, Gennat H, O'Rourke P, Del Mar C. Exercise for overweight or obesity. Cochrane Database Syst Rev. 2006:4:4.

3. Luepker RV. Minnesota, a good place for your heart: trends in cardiovascular disease. J Cardiovasc Transl Res. 2008;1(4):301-4.

4. Arrigo I, Brunner-LaRocca H, Lefkovits M, Pfisterer M, Hoffmann A. Comparative outcome one year after formal cardiac rehabilitation: the effects of a randomized intervention to improve exercise adherence. Eur J Cardiovasc Prev Rehabil. 2008;15(3):306-11.

5. Piperidou $\mathrm{E}, \mathrm{Bliss} \mathrm{J}$. An exploration of exercise training effects in coronary heart disease. Br J Community Nurs. 2008;13(6):271-7.

6. Ades PA, Savage PD, Toth MJ, Harvey-Berino J, Schneider DJ, Ludlow M. High-calorie-expenditure exercise: A new approach to cardiac rehabilitation for overweight coronary patients. Circulation. 2009;119:2671-8.

7. American Heart Association. Heart Disease and Stroke Statistics-2012 Update: a report from the American Heart Association. Circulation. 2012; 125:e2-e220.

8. Kokkinos PF, Giannelou A, Manolis A, Pittaras A. Physical activity in the prevention and management of high blood pressure. Hellenic J Cardiol. 2009;50(1):52-9.
9. Marshall AL, Booth ML, Bauman AE. Promoting physical activity in Australian general practices: a randomised trial of health promotion advice versus hypertension management. Patient Educ Couns. 2005;56(3):283-90.

10. Allen JK, Scott LB, Stewart KJ, Young DR. Disparities in women's referral to and enrollment in outpatient cardiac rehabilitation. J Gen Intern Med. 2004; 19(7):747-53.

11. Thomas RJ. Cardiac rehabilitation/secondary prevention programs a raft for the rapids: Why have we missed the boat? Circulation. 2007;116(15):1644-6.

12. Wenger N. Current status of cardiac rehabilitation. J Am Coll Cardiol. 2008; 51(17):1619-31.

13. Shishani K. Cardiovascular nursing in Jordan: a need for an action. TAF Prev Med Bull. 2010;9(5):523.

14. Alsaleh $\mathrm{E}$, Alhasan M. Perceived benefits of and barriers to exercise among patients with coronary heart disease. Master Dissertation. Jordan University of Science and Technology. 2006.

15. Ammouri AA, Neubergar G, Nashwan JA. Determinants of self-reported physical activity among Jordanian adults. J Nurs Scholarsh. 2007:39(41):342-8.

16. Conn VS, Hafdahl AR, Brown SA, Brown LM. Meta-analysis of patient education interventions to increase physical activity among chronically ill adults. Patient Educ Couns. 2008;70(2):157-72.

17. Blanchard CM, Reid RD, Morrin LI, McDonnell L, McGannon K, Rhodes RE, Edwards N. Demographic and clinical determinants of moderate to vigorous physical activity during home-based cardiac rehabilitation: the home-based determinants of exercise (HOME) study. J Cardiopulm Rehabil Prev. 2010;30(4):240-5.

18. Rodrigues RC, Joao TM, Gallani MC, Cornélio ME, Alexandre NM. The "Moving Heart Program": an intervention to improve physical activity among patients with coronary heart disease. Rev Lat Am Enfermagem. 2013:21:180-90.

19. Bodenheimer T, Handley MA. Goal-setting for behaviour change in primary care : An exploration and status report. Patient Educ Couns. 2009;76:174-80.

20. Lock EA, Latham GP. Building a practically useful theory of goal-setting and task motivation. Am Psychol. 2002;57(9):705-17.

21. Lunenburg FC. Goal setting theory of motivation. Int J Manag Bus Administration. 2011;15(1):1-6.

22. Luszczynska A. An implementation intentions intervention, the use of a planning strategy, and physical activity after myocardial infarction. Soc Sci Med. 2006;62(4):900-8.

23. Sniehotta FF, Scholz U, Schwarzer R, Fuhrmann B, Kiwus U, Völler H. Long-term effects of two psychological interventions on physical exercise and selfregulation following coronary rehabilitation. Int J Behav Med. 2005;12(4):244-55.

24. Sniehotta FF, Scholz U, Schwarzer R. Action plans and coping plans for physical exercise: A longitudinal intervention study in cardiac rehabilitation. Br J Health Psychol. 2006;11(Pt 1):23-37.

25. Shilts MK, Horowitz M, Townsend MS. Goal setting as a strategy for dietary and physical activity behaviour change: a review of the literature. Am J Health Promot. 2004;19(2):81-93.

26. Artinan NT, Fletcher GF, Mozaffarian D, Kris-Etherton P, Van Horn L, Lichtenstein AH. Burke, LE. Interventions to promote physical activity and dietary lifestyle changes for cardiovascular risk factor reduction in adults: a scientific statement from the American Heart Association. Circulation. 2010; 122(4):406-41.

27. Furber S, Butler L, Phongsavan P, Mark A, Bauman A. Randomised controlled trial of a pedometer-based telephone intervention to increase physical activity among cardiac patients not attending cardiac rehabilitation. Patient Educ Couns. 2010;80(2):212-8.

28. Blake H, Sugg, LS, Coman E, Aguirre L, Batt ME. Active8! Technology-based intervention to promote physical activity in hospital employees. Am J Health Promot. 2015. In Press.

29. Giallauria F, Lucci R, Pilerci F, De Lorenzo A, Manakos A, Psaroudaki M, Vigorito C. Efficacy of telecardiology in improving the results of cardiac rehabilitation after acute myocardial infarction. Monaldi Arch Chest Dis. 2006;66(1):8-12.

30. Hughes AR, Mutrie N, Macintyre PD. Effect of an exercise consultation on maintenance of physical activity after completion of phase III exercise-based cardiac rehabilitation. Eur J Cardiovasc Prev Rehabil. 2007;14(1):114-21.

31. Oliveira J, Ribeiro F, Gomes H. Effects of a home-based cardiac rehabilitation program on the physical activity levels of patients with coronary artery disease. J Cardiopulm Rehabil Prev. 2008;28(6):392-6.

32. Reid RD, Morrin LI, Higginson LA, Wielgosz A, Blanchard C, Beaton LJ, Pipe AL. Motivational counselling for physical activity in patients with coronary 
artery disease not participating in cardiac rehabilitation. Eur J Prev Cardiol. 2012;19(2):161-6.

33. Schulz KF, Altman DG, Moher D. CONSORT 2010 statement: updated guidelines for reporting parallel group randomised trials. BMC Med. 2010;8(1):1.

34. Ferrier S, Blanchard C, Vallis M, Giacomantonio N. Behavioural interventions to increase the physical activity of cardiac patients: a review. Eur J Cardiovasc Prev Rehabil. 2011;18(1):15-32.

35. Balady GJ, William AK, Ade PA, Bittner V. American Heart Association/ AACVPR scientific statement: Core components of cardiac secondary prevention program. Circulation. 2007;115:2675-82.

36. Shiroma EJ, Lee IM. Physical activity and cardiovascular health lessons learned from epidemiological studies across age, gender, and race/ethnicity. Circulation. 2010;122(7):743-52.

37. Bandura A. Self-efficacy: toward a unifying theory of behavioural change. Psychol Rev. 1977;84(2):2.

38. Bandura A. Health promotion by social cognitive means. Health Educ Behav. 2004;31(2):143-64.

39. Ajzen I. The theory of planned behaviour. Organ Behav Hum Decis Process. 1991;50(2):179-211.

40. Ajzen I. Nature and operation of attitudes. Annu Rev Psychol. 2001;52(1):27-58.

41. Head KJ, Noar SM, lannarino NT, Grant HN. Efficacy of text messaging-based interventions for health promotion: a meta-analysis. Soc Sci Med. 2013;97:41-8.

42. IPAQ. 2000. http://www.sdp.univ.fvg.it/sites/default/files/IPAQ_English_selfadmin_short.pdf. Accessed 24 Feb 2013.

43. Helmerhorst HJ, Brage S, Warren J, Besson H, Ekelund U. A systematic review of reliability and objective criterion-related validity of physical activity questionnaires. Int J Behav Nutr Phys Act. 2012;9(1):103-57.

44. Resnick $B$, Jenkins LS. Testing the reliability and validity of the self-efficacy for exercise scale. Nurs Res. 2000;49(3):154-9.

45. Valenti L, Lim L, Heller RF, Knapp J. An improved questionnaire for assessing quality of life after acute myocardial infarction. Qual Life Res. 1996;5(1):151-61.

46. Hofer S, Lim L, Guyatt G, Oldridge N. The MacNew Heart Disease healthrelated quality of life instrument: a summary. Health Qual Life Outcomes. 2004;2:3.

47. McConnell TR, Laubach CA, Memon M, Gardner JK, Klinger TA, Palm RJ. Quality of life and self efficacy in cardiac rehabilitation patients over 70 years of age following acute myocardial infarction and bypass revascularization surgery. Am J Geriatr Cardiol. 2000;9(4):210-8.

48. Pickering TG, Hall JE, Appel LJ, Falkner BE, Graves J, Hill MN, Roccella EJ. Recommendations for blood pressure measurement in humans and experimental animals part 1: blood pressure measurement in humans: a statement for professionals from the Subcommittee of Professional and Public Education of the American Heart Association Coun. Hypertension. 2005;45(1):142-61.

49. British Hypertension Society. Poster: Measuring blood pressure using a digital monitor. http://www.bhsoc.org/resources/how-to-measure-bloodpressure/. 2012. Accessed Dec 2012.

50. Medicines and Health Care Products Regulatory Agency (MHRA). Blood pressure measurement devices. 2013. https://www.gov.uk/government/ uploads/system/uploads/attachment_data/file/403448/Blood_pressure_ measurement_de. Accessed 22 Mar 2012.

51. O'Brien E, Asmar R, Beilin L, Imai Y, Mallion JM, Mancia G, Verdecchia P. European Society of Hypertension recommendations for conventional, ambulatory and home blood pressure measurement. J Hypertens. 2003; 21(5):821-48.

52. Lavie CJ, Milani RV, Artham SM. Combating the obesity paradox: benefits and safety of purposeful weight loss in overweight and obese coronary patients. J Am Coll Cardiol. 2008;51(10):A 367.

53. Lee PH, Macfarlane DJ, Lam TH, Stewart SM. Validity of the International Physical ActivityQuestionnaire Short Form (IPAQ-SF): a systematic review. Int J Behav Nutr Phys Act. 2011:8(1):115.

54. Scholz U, Knoll N, Sniehotta FF, Schwarzer R. Physical activity and depressive symptoms in cardiac rehabilitation: long-term effects of a self-management intervention. Soc Sci Med. 2006;62(12):3109-20.

55. Pereira MA, Fitzgerald SJ, Gregg E, et al. Seven-day physical activity recall. Med Sci Sports Exerc. 1997;29:89-103.

56. Yates BC, Anderson T, Hertzog M, Ott C, Williams J. Effectiveness of followup booster sessions in improving physical status after cardiac rehabilitation: health, behavioural, and clinical outcomes. Appl Nurs Res. 2005;18(1):59-62.
57. Heath GW, Maloney PM, Fure CW. Group exercise versus home exercise in coronary artery bypass graft patients: effects on physical activity habits. J Cardiopulm Rehabil Prev. 1987;7(4):190-5.

58. Metkus TS, Baughman KL, Thompson PD. Exercise prescription and primary prevention of cardiovascular disease. Circulation. 2010;121(23):2601-4.

59. Thompson PD. Exercise prescription and proscription for patients with coronary artery disease. Circulation. 2005;112(15):2354-63.

60. Greaves CJ, Sheppard KE, Abraham C, Hardeman W, Roden M, Evans PH, Schwarz P. Systematic review of reviews of intervention components associated with increased effectiveness in dietary and physical activity interventions. BMC Public Health. 2011;11(1):119.

61. Van Der Bij AK, Laurant MG, Wensing M. Effectiveness of physical activity interventions for older adults. Am J Prev Med. 2002;22(2):120-33.

62. Prestwich A, Perugini M, Hurling R. Can implementation intentions and text messages promote brisk walking? A randomized trial. Health Psychol. 2010; 29(1):40-9.

63. Jolly K, Taylor R, Lip GYH, Greenfield S, Raftery J, Mant J, et al. The Birmingham Rehabilitation Uptake Maximisation Study (BRUM) Home-based compared with hospital-based cardiac rehabilitation in a multi-ethnic population. Gray Pub. 2007;11(35):1-118.

64. Hanssen TA, Nordrehaug JE, Eide GE, Hanestad BR. Improving outcomes after myocardial infarction: a randomized controlled trial evaluating effects of a telephone follow-up intervention. Eur J Cardiovasc Prev Rehabil. 2007; 14(3):429-37.

65. Centre for Disease Control and Prevention CDC. Health related quality of life. http://www.cdc.gov/hrqol/concept.htm. 2011. Accessed 10 August 2011.

66. Sanders C, Egger M, Donovan J, Tallon D, Frankel S. Reporting on quality of life in randomised controlled trials: bibliographic study. BMJ. 1998; 317(7167):1191-4.

67. Cornelissen VA, Fagard RH. Effects of endurance training on blood pressure, blood pressure-regulating mechanisms, and cardiovascular risk factors. Hypertension. 2005;46(4):667-75.

68. Fagard $\mathrm{RH}$, Cornelissen VA. Effect of exercise on blood pressure control in hypertensive patients. Eur J Cardiovasc Prev Rehabil. 2007;14(1):12-7.

69. Clark AM, Haykowsky M, Kryworuchko J, MacClure T, Scott J, DesMeules M, McAlister FA. A meta-analysis of randomized control trials of home-based secondary prevention programs for coronary artery disease. Eur J Cardiovasc Prev Rehabil. 2010;17(3):261-70.

70. Lavie CJ, Milani RV. Effects of cardiac rehabilitation, exercise training, and weight reduction on exercise capacity, coronary risk factors, behavioural characteristics, and quality of life in obese coronary patients. Am J Cardiol. 1997;79(4):397-401.

71. Manzoni GM, Villa V, Compare A, Castelnuovo G, Nibbio F, Titon AM, Gondoni LA. Short-term effects of a multi-disciplinary cardiac rehabilitation programme on psychological well-being, exercise capacity and weight in a sample of obese in-patients with coronary heart disease: a practice-level study. Psychol Health Med. 2011;16(2):178-89.

72. Franklin B, Bonzheim K, Warren J, Haapaniemi S, Byl N, Gordon N. Effects of a contemporary, exercise-based rehabilitation and cardiovascular riskreduction program on coronary patients with abnormal baseline risk factors. CHEST J. 2002;122(1):338-43.

73. Nielsen KM, Faergeman O, Foldspang A, Larsen ML. Cardiac rehabilitation: health characteristics and socio-economic status among those who do not attend. Eur J Pub Health. 2008;18(5):479-83.

74. Allison MJ, Keller C. Self-efficacy intervention effect on physical activity in older adults. West J Nurs Res. 2004;26:31-46.

75. Gary R. Exercise self-efficacy in older women with diastolic heart failure. $J$ Gerontol Nurs. 2006;32(7):31-9. 